\title{
PARFOR NA AMAZÔNIA PARAENSE: contribuições para a qualidade da educação do município de Óbidos-PA
}

\author{
Aline da Silva Ferreira \\ Iamilia Brito de Oliveira \\ Lilian Aquino de Oliveira)
}

\section{Resumo}

Este estudo objetivou conhecer e analisar as contribuições do Parfor para o campo educacional paraense, tendo como ponto de partida as práticas desenvolvidas no município de Óbidos-Pará, no recorte temporal compreendido entre 2010 a 2019, considerando os resultados das avaliações de larga escala. A investigação foi desenvolvida com abordagem quanti-qualitativa, por meio de pesquisa bibliográfica, documental e empírica, incluindo a aplicação de entrevistas tanto a sujeitos previamente determinados quanto definidos aleatoriamente. Entre os resultados, tem-se que o Parfor teve expressiva contribuição quantitativa para a formação do quadro docente, e as conclusões são que efeitos sobre a educação municipal são mais elucidados no aspecto quantitativo, de modo mais contundente no primeiro ciclo do ensino fundamental.

Palavras-chave: parfor; avaliação de larga escala; qualidade.

\section{PARFOR IN AMAZÔNIA PARAENSE: contributions to the quality of education in the municipality of Óbidos-PA}

\begin{abstract}
This study aimed to know and analyze Parfor's contributions to the educational field in Pará, taking as a starting point the practices developed in the municipality of Óbidos-Pará, in the time frame between 2010 to 2019, considering the results of large-scale evaluations. The investigation was developed with a quantitative-qualitative approach, through bibliographic, documentary and empirical research, including the application of interviews both to previously determined and randomly defined subjects. Among the results, Parfor had an expressive quantitative contribution to the formation of the teaching staff, and the conclusions are that the effects on municipal education are more elucidated in the quantitative aspect, in a more striking way in the first cycle of fundamental education.
\end{abstract}

Keywords: parfor; large-scale evaluation; quality.

PARFOR AMAZÔNIA PARAENSE: contribuciones a la calidad de la educación en el municipio de Óbidos-Pará

\section{Resumen}

Este estudio tuvo como objetivo conocer y analizar las contribuciones de Parfor al campo educativo en Pará, tomando como punto de partida las prácticas desarrolladas en el municipio de Óbidos-Pará, en el período comprendido entre 2010 y 2019, considerando los resultados de las evaluaciones a gran escala. La investigación se desarrolló con un enfoque cuantitativo-cualitativo, a través de la investigación bibliográfica, documental y empírica, incluida la aplicación de entrevistas tanto a sujetos previamente determinados como aleatoriamente definidos. Entre los resultados, Parfor tuvo una contribución cuantitativa expresiva a la formación del personal docente, y las conclusiones son que los efectos sobre la educación municipal se aclaran más en el aspecto cuantitativo, de una manera más llamativa en el primer ciclo de la educación fundamental.

Palabras clave: parfor; evaluación a gran escala; calidad. 


\section{INTRODUÇÃO}

A qualificação do professor tem ocupado lugar de destaque no debate educacional brasileiro nas últimas décadas, sobretudo a partir do reconhecimento da educação como direito de todo os cidadãos, por ser entendida como principal meio para possibilitar o sucesso das demais políticas educacionais. Por isso, no âmbito da política nacional para a formação de professores no Brasil, diversos programas foram desenvolvidos com o objetivo de promover a formação inicial e continuada para docentes da educação básica.

Em prol deste objetivo, um dos programas federais com maior destaque e alcance nos últimos anos é o Programa Nacional de Formação de Professores da Educação Básica (Parfor), ofertado na modalidade de ensino presencial, observando sua capacidade de expandir direitos, reduzir desigualdades regionais e propiciar equidade no acesso à formação de professores para a educação básica, conforme declarado no inciso IX, Artigo $2^{\circ}$ do Decreto n. 6.755/2009 (BRASIL, 2009), que institui a Política Nacional de Formação de Profissionais do Magistério da Educação Básica.

Para os estados das regiões norte e nordeste, que apresentam historicamente maiores déficits de oferta de educação superior, o programa tem se mostrado uma alternativa eficiente do ponto de vista quantitativo para elevação nos índices de professores com formação em graduação.

Formulado em 2009, no âmbito da Coordenação de Aperfeiçoamento de Pessoal de Nível Superior - CAPES/MEC, o Parfor compreende um conjunto de ações do governo federal, em colaboração com as Instituições de Ensino Superior (IES) públicas e secretarias de educação de estados e municípios, para desenvolver cursos superiores e de formação continuada aos docentes em serviço. Além disso, busca ampliar a oferta de educação superior, gratuita e de qualidade, para que os professores da rede pública de educação básica possam atender à formação exigida pela Lei de Diretrizes e Bases da Educação Nacional - LDB, n. 9.394/96, que estabelece:

A formação de docentes para atuar na educação básica far-se-á em nível superior, em curso de licenciatura, de graduação plena, em universidades e institutos superiores de educação, admitida, como formação mínima para o exercício do magistério na educação infantil e nas quatro primeiras séries do ensino fundamental, oferecida em nível médio, na modalidade Normal (Art. 62).

Em relação ao Município de Óbidos-Pará, de acordo com o Observatório do Plano Nacional da Educação - $\mathrm{PNE}^{1}$, o índice de professores que atuam na educação básica com formação em nível superior (bacharelado ou licenciatura) cresceu de 29,2\% em 2010 para $71 \%$ em 2017. Logo, apenas $29 \%$ dos professores que atuam no quadro da educação básica do município ainda não possuem formação em nível superior.

Por outro lado, segundo o Instituto Nacional de Estudos e Pesquisas Educacionais Anísio Teixeira - Inep, o município de Óbidos em 2017 apresentou um Índice de Desenvolvimento da Educação Básica - Ideb de 4.8 para o ensino fundamental anos iniciais e 3.6 para o ensino fundamental anos finais. De acordo com o próprio Instituto, a meta projetada seria de 4.4 para os anos iniciais e de 5.1 para os anos finais do ensino fundamental. Esses dados, associados aos dados observados, em comparação com os dados projetados, mostram que o município está muito aquém

${ }^{1}$ O Observatório do PNE é uma plataforma online que tem como objetivo monitorar os indicadores referentes a cada uma das 20 metas estabelecidas pelo Plano Nacional de Educação (Lei n. 13.005/2014) e suas respectivas estratégias. 
da meta nacional. Conforme o atual PNE, todas as escolas deveriam, no ano de 2021, alcançar a média 6.0 no índice para ensino fundamental anos iniciais e 5.5 para o ensino fundamental anos finais.

Feitas estas considerações iniciais, o presente trabalho debruça-se sobre o Programa Nacional de Formação de Professores da Educação Básica - Parfor, objetivando conhecer e analisar suas contribuições para o campo educacional paraense. Para tanto, observa-se como ponto de partida o estudo das práticas desenvolvidas no município de Óbidos, localizado na região oeste do estado do Pará, no recorte temporal compreendido entre 2010 a 2019, considerando os resultados das avaliações de larga escala.

Registrado o ingresso de 554 acadêmicos e a diplomação de 443 profissionais por meio do programa, algumas indagações se fazem pertinentes: Quais as contribuições da formação de profissionais da educação básica realizada pelo Parfor na qualidade da educação básica no Município de Óbidos - Pará? Quais as opiniões do gestor e coordenadores pedagógicos da Secretaria Municipal de Educação - Semed sobre a contribuição do programa para a formação de quadros docentes da educação básica no município, e sobre sua repercussão na qualidade da educação básica? O que dizem os egressos do Parfor sobre as contribuições do programa para prática profissional?

Para embasar esta produção, foi realizada pesquisa junto à coordenação do Parfor no município de Óbidos-Pará e Secretaria Municipal de Educação. De natureza quanti-qualitativa, o estudo constitui-se por pesquisa bibliográfica, documental e empírica. A pesquisa documental possibilitou analisar documentação elaborada para o uso da Coordenação Municipal do Parfor e da Semed, do município lócus, como: registros estatísticos, atos jurídicos, documentos institucionais mantidos na Semed, entre outros, referentes ao quantitativo de profissionais formados pelo Parfor e atuantes no quadro de professores do município, e, ainda, os procedimentos tomados pelo poder executivo municipal na implementação do programa.

Foram aplicadas entrevistas semiestruturadas aos seguintes sujeitos da pesquisa: coordenadora pedagógica das escolas da zona urbana, cujas falas são identificadas nesta produção com a sigla "CP-ZU"; o gestor (secretário municipal de educação), cujas falas são identificadas com a sigla "G-SEMED"; e um técnico em assuntos educacionais, também ex-gestor da Semed no período em que as turmas do Parfor estavam em execução, cujas falas são identificadas com a sigla "EX-G-SEMED".

Também foram aplicados questionários a um professor de cada escola da zona urbana, totalizando uma amostra de 14 professores da educação infantil e ensino fundamental (anos iniciais e anos finais), formados pelo programa. Os respondentes foram selecionados por amostra aleatória e a aplicação da técnica teve como finalidade identificar as opiniões dos egressos sobre as contribuições do programa para a prática profissional. Nesta construção textual, as falas destes sujeitos serão identificadas pelas iniciais SP, seguida de numeração cardinal para cada sujeito.

As falas dos entrevistados estão dispostas no texto em itálico, como maneira de diferenciar das citações literais dos autores que compõem o referencial teórico do estudo. Tanto as entrevistas quanto os questionários aplicados foram validados através de opinião de especialistas no tema e todos os participantes do estudo assinaram Termo de Consentimento Livre e Esclarecido - TCLE.

Os dados obtidos por meio das entrevistas, questionários e pesquisas bibliográficas foram confrontados, através de triangulação, com aqueles obtidos na pesquisa documental e nos resultados das avaliações de larga escala, bem como com os indicadores do observatório do PNE. 
O estudo está fundamentado em autores que corroboram com a perspectiva de que as políticas públicas voltadas para a formação e para a qualificação de professores durante as últimas décadas não têm respondido suficientemente aos problemas relacionados à educação básica do país, como Borges (2013), Libâneo (2013), Gatti (2015) e Imbernón (2016).

A análise dos dados qualitativos preocupou-se em identificar quais os efeitos que os dados quantitativos apresentados imprimem na qualidade da educação básica do município, com base nos resultados das avaliações de larga escala.

Além das seções introdutória e conclusiva, o artigo contempla quatro seções. A primeira apresenta dados relativos à oferta quantitativa dos cursos promovidos através do programa. $\mathrm{Na}$ segunda, explora-se dados relativos às contribuições do Parfor para a formação do quadro docente no município. A terceira seção aborda a relação entre o Parfor e os resultados municipais nas avaliações de larga escala. Por último, na quarta seção, evidenciam-se as contribuições do Parfor no desempenho da atividade docente no município de Óbidos, a partir da óptica dos egressos do programa.

\section{A OFERTA DO PARFOR NO MUNICÍPIO DE ÓBIDOS-PARÁ}

Dada a determinação contida no Art. 62 da Lei n. 9.394/1996, o Programa Nacional de Formação de Professores da Educação Básica - Parfor foi criado a fim de colaborar para garantir a formação mínima exigida para o magistério na educação básica através da oferta gratuita de cursos de graduação a docentes que já atuam nas escolas públicas, mas não possuem os requisitos legais de formação.

O município de Óbidos aderiu ao programa no ano de 2009, e, no ano de 2010, foram formadas as primeiras turmas de cursos de graduação nas áreas de Pedagogia, História e Geografia, Biologia e Química, Matemática e Física e Letras - Português e Inglês. Em 2011, foram formadas mais cinco turmas nas mesmas áreas, além de turmas nos cursos de: (uma turma) Licenciatura Integrada em Letras - Português e Inglês, (uma turma) Licenciatura Integrada História e Geografia e (uma turma) Licenciatura Integrada Biologia e Química.

Em julho de 2012, ingressou mais uma turma de Licenciatura em Pedagogia, uma de Licenciatura Integrada História e Geografia e uma de Licenciatura Integrada Matemática e Física.

Em 2015, a Universidade Federal do Pará (UFPA), em parceria com o município, ofertou 33 vagas para o curso de Licenciatura em Música, totalizando o quantitativo de 555 vagas ofertadas para o município de Óbidos, através da Universidade Federal do Oeste do Pará - Ufopa e da Universidade Federal do Pará. Os dados de ingresso por curso/ano estão sintetizados na Tabela 1: 
DOI: $10.12957 /$ teias.\%Y.50163

Tabela 1 - Quantitativo de Ingressantes por curso e ano nas ofertas pelo Parfor no município de Óbidos

\begin{tabular}{lccccccc}
\hline \multirow{2}{*}{ Cursos } & \multicolumn{7}{c}{ Anos } \\
\cline { 2 - 8 } & $\mathbf{2 0 1 0}$ & $\mathbf{2 0 1 1}$ & $\mathbf{2 0 1 2}$ & $\mathbf{2 0 1 3}$ & $\mathbf{2 0 1 5}$ & Total \\
\hline$\quad$ Pedagogia & 50 & 45 & 45 & 28 & - & 168 \\
LI em História e Geografia & 50 & 41 & 32 & - & - & 123 \\
LI em Letras - & 50 & 41 & - & - & - & 91 \\
$\quad \begin{array}{c}\text { Português/Inglês) } \\
\text { LI em Matemática e Física }\end{array}$ & 50 & - & 36 & - & - & 86 \\
LI em Biologia e Química & 31 & 22 & - & - & - & 53 \\
Música & - & - & - & - & 34 & 34 \\
Total & 231 & 149 & 113 & 28 & 34 & 555 \\
\hline
\end{tabular}

Fonte: Autores - 2019.

Nota: LI - Licenciatura Integrada

O curso de Licenciatura em Pedagogia foi o que mais disponibilizou vagas, ofertou um quantitativo de 168 vagas, seguido do curso de Licenciatura Integrada em História e Geografia 123 vagas; Licenciatura Integrada em Letras - Português/Inglês - 91 vagas; Licenciatura Integrada em Matemática e Física - 86 vagas; Licenciatura Integrada em Biologia e Química - 53 vagas e Música - 34 vagas.

Cabe ressaltar que somente a Ufopa ofertou cursos na forma de Licenciaturas Integradas, cuja modalidade visa integrar os conhecimentos de áreas distintas e afins, diferentemente das instituições superiores de outras regiões, que implantaram cursos específicos em uma única área de formação.

\section{A FORMAÇÃO DE QUADROS DE PROFESSORES NO MUNICÍPIO DE ÓBIDOS ATRAVÉS DO PARFOR}

O Observatório do PNE aponta que, até o ano de 2017, somente 29\% dos professores que atuam no município ainda não possuíam formação em nível superior e, conforme dados da Coordenação Local do Parfor no município, no ano de 2019, dos atuais 554 professores da rede pública municipal, 443 profissionais foram formados pelo programa no período de 2010 a 2019, na cronologia registrada pela tabela a seguir: 
DOI: $10.12957 /$ teias.\%Y.50163

Tabela 2 - Quantitativo de concluintes dos cursos ofertados pelo Parfor no município de Óbidos

\begin{tabular}{cccccccc}
\hline Cursos & \multicolumn{7}{c}{ Anos } \\
\cline { 2 - 7 } & $\mathbf{2 0 1 0}$ & $\mathbf{2 0 1 1}$ & $\mathbf{2 0 1 2}$ & $\mathbf{2 0 1 3}$ & $\mathbf{2 0 1 5}$ & Total \\
\hline Pedagogia & 47 & 42 & 32 & 23 & - & 144 \\
LI em História e Geografia & 41 & 37 & 18 & - & - & 95 \\
LI em Letras - & 39 & 34 & - & - & - & 73 \\
Português/Inglês) & & & & & & \\
LI em Matemática e Física & 49 & - & 20 & - & - & 69 \\
LI em Biologia e Química & 22 & 14 & - & - & - & 36 \\
Música & - & - & - & - & 26 & 26 \\
Total & 198 & 127 & 70 & 23 & 26 & 443 \\
\hline
\end{tabular}

Fonte: Autores - 2019.

Nota: LI - Licenciatura Integrada

Os relatórios ${ }^{2}$ emitidos pela Secretaria Municipal de Educação, analisados neste estudo, comprovam que, dos 443) profissionais formados pelo Parfor, 58,2\% (258) ainda fazem parte do quadro de professores da educação básica do município, dos quais 72,1\% (186) são funcionários efetivos e $27,9 \%$ (72) são funcionários contratados, até a data da emissão do relatório. Destes, $41,5 \%$ (107) estão lotados na zona urbana e 58,5\% (151) estão lotados na zona rural, na educação infantil e ensino fundamental (anos iniciais e anos finais).

Em busca de entender as razões pelas quais $41,8 \%$ dos docentes qualificados por meio do Parfor não integram o quadro de professores do município, apuramos por meio de dados verbais que: a) há professores que se desligaram da rede municipal; b) outros, apesar de terem cursado o Parfor em Óbidos, eram originários de outros municípios; c) alguns se aposentaram; d) outros eram funcionários contratados e, por questões políticas, hoje já não fazem mais parte do quadro; e) muitos não estão na sala de aula, têm outras profissões, alguns estão como gestores, outros como coordenadores. No entanto, não existem assentamentos formais ou estatísticas que registrem essas situações.

O fato de questões políticas interferirem na contratação dos professores mostra que a pactuação entre o município e os demais entes da federação sobre a formação destes profissionais é esvaziada, a qualidade e o investimento feito na formação deixam de ser a prioridade e outro viés ocupa o lugar central nessa decisão: as relações políticas estabelecidas. Com isso, identificamos mais um dos graves problemas que a política educacional vem enfrentando ao longo da história por parte dos governantes, que conseguem ser suficientemente capazes de elaborar discursos que enaltecem a educação, mas na prática não a fazem peça fundamental na engrenagem da máquina pública para a construção de sociedade mais justa e igualitária.

Some-se a isso a falha da gestão municipal em não alocar os recém-formados em suas respectivas áreas de formação - ou seja, o município, no momento da lotação de professores, não parte deste pressuposto, como também não promove concurso público para regularização docente, prevalecendo lotações antigas, mantendo a mesma disparidade entre área de formação e área de

\footnotetext{
${ }^{2}$ Relatórios emitidos pela Secretaria Municipal de Educação do município de Óbidos, em 27 de junho de 2019, para esta pesquisa.
} 
atuação, - em uma realidade em que 35,72\% dos egressos do Parfor atuam em área distinta da sua formação.

É inegável a contribuição quantitativa do programa para o quadro docente do município, no entanto, esse quantitativo poderia ser mais elevado se, conforme os gestores entrevistados, todos os profissionais formados pelo programa, mesmo que com vínculo de trabalho temporário, fossem mantidos no quadro de professores.

A flexibilidade quanto à seleção dos professores para o ingresso no programa de formação, em relação ao tipo de vínculo trabalhista (efetivo ou contratado), influencia na permanência dos profissionais no quadro, pois as "questões políticas", na maioria das vezes, não consideram a qualificação do profissional.

\section{O PARFOR E OS RESULTADOS DAS AVALIAÇÕES DE LARGA ESCALA}

Sob a justificativa de alcançar a qualidade da educação, o Estado brasileiro investiu em um complexo Sistema de Avaliação da Educação Básica - Saeb, voltado a diagnosticar a qualidade da educação a partir de uma visão limitada aos resultados obtidos, geralmente ignorando os processos educacionais desenvolvidos nas instituições escolares.

A partir dos exames integrantes do Saeb, é calculado o Índice de Desenvolvimento da Educação Básica - Ideb, com a finalidade de medir a qualidade do ensino e estabelecer metas que impulsionem sua melhoria. As instituições escolares são avaliadas bienalmente e, até o ano de 2022, tem-se como meta que todas as escolas alcancem a média 6,0.

Cria-se, portanto, a obrigatoriedade para que estados e municípios assumam responsabilidades e definam estratégias para se alcançar os resultados esperados, conforme explicita Gatti:

Estados e municípios, diretamente responsáveis pela manutenção e pelo desenvolvimento da educação básica, passam, com isso, a ser mais incisivamente submetidos a uma forma de obrigação de resultados, baseada em indicadores padronizados de rendimento, induzindo a uma progressão orientada por metas quantitativas, com vistas ao alcance de determinado padrão de qualidade. $\mathrm{O}$ grande desafio da educação no país - a melhoria da qualidade do ensino - tende, portanto, a traduzir-se fundamentalmente no seu equacionamento em termos da capacidade de alcançar um bom resultado na pontuação do Ideb (2011, p. 41).

A partir dos indicadores gerados pelo Saeb, pode-se, teoricamente, inferir sobre a qualidade da educação em diferentes aspectos, entre eles, aqueles que se referem à qualificação profissional dos docentes e sua relação com a qualidade da educação ofertada.

Dada a contribuição quantitativa do Parfor para a formação acadêmica dos professores da rede pública do município de Óbidos, também convém investigar sobre contribuições de natureza qualitativa propiciada por esta formação.

Os sujeitos entrevistados declaram que o programa contribui para a qualidade do ensino local, porém, ainda existem fatores que precisam melhorar: "Qualitativamente o Parfor contribuiu, mas não 100\%” (CP-ZU).

O Parfor contribui para que a educação do município melhorasse a sua qualidade, no entanto ainda temos muito a melhorar. Isso se dá pelo fato de alguns profissionais que fazem parte do 
nosso quadro não colocarem em prática na sala de aula os conbecimentos que adquiriram em sua formação (G-SEMED).

Com o programa em atividade, o Município ganhou não apenas em qualidade com um maior número de profissionais com graduação, neste sentido é inegável que o Parfor tenha contribuido para a melhora deste indice de professores com a qualificação minima exigida [...] Outros aspectos importantes deste programa foi a grande oportunidade, principalmente, para os profissionais dos interiores, onde a educaşão superior muitas vežes não chegam para que pudessem ter acesso a um mundo novo de conhecimento, bem como, o fato de a universidade ter permitido também aos acadêmicos vivências fora do espaço da sala de aula (EX-G-SEMED).

As declarações reforçam as conclusões sobre as melhorias oportunizadas pelo programa para o ensino público do município no que se refere ao número de profissionais com formação adequada do ponto de vista da legislação. Conforme os entrevistados:

Em relação ao Índice de Desenvolvimento da Educação Básica, o Ideb, acredito, plenamente que a formaşão dos professores pelo Parfor contribuiu bastante para que o Ideb do município melhorasse. Infelizmente, ainda não está como queremos, estamos trabalhando para que alcance as metas projetadas, mas, não temos como negar que teve uma evolução a partir da formação dos professores do quadro" (CP-ZU).

A formacão dos professores que fazem parte do município pelo programa Parfor contribui para que o Ideb melhorasse, no entanto ainda estamos distantes do resultado estipulado que é 6.0 até 2020. (EX-G-SEMED)

Todavia, há contradição entre o índice de qualificação do corpo docente (somente $29 \%$ dos professores da educação básica não possuem nível superior, conforme dados apresentados pelo Inep) e o desempenho do município na avaliação de larga escala. De acordo com os dados do Inep, em relação ao ensino fundamental dos anos iniciais, o município, dos anos de 2007 a $2017^{3}$, supera as metas projetadas, apresentando em 2017 Ideb de 4.8:

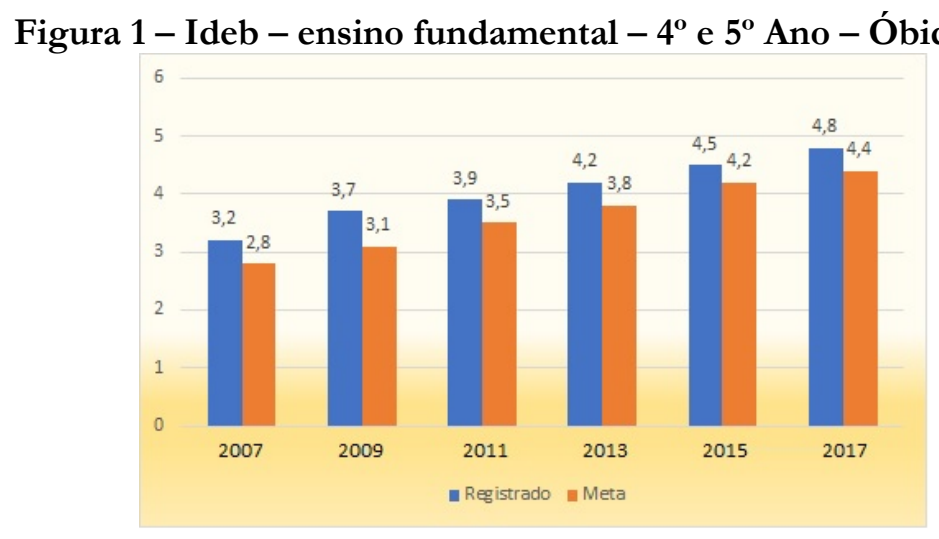

Fonte: Inep.

\footnotetext{
${ }^{3}$ http://ideb.inep.gov.br/resultado/resultado/resultado.seam?cid=1739631. Acesso em 22 nov. 2018.
} 
Já os anos finais do ensino fundamental apresentam quadro crítico em relação aos índices, pois não conseguiu atingir as metas projetadas:

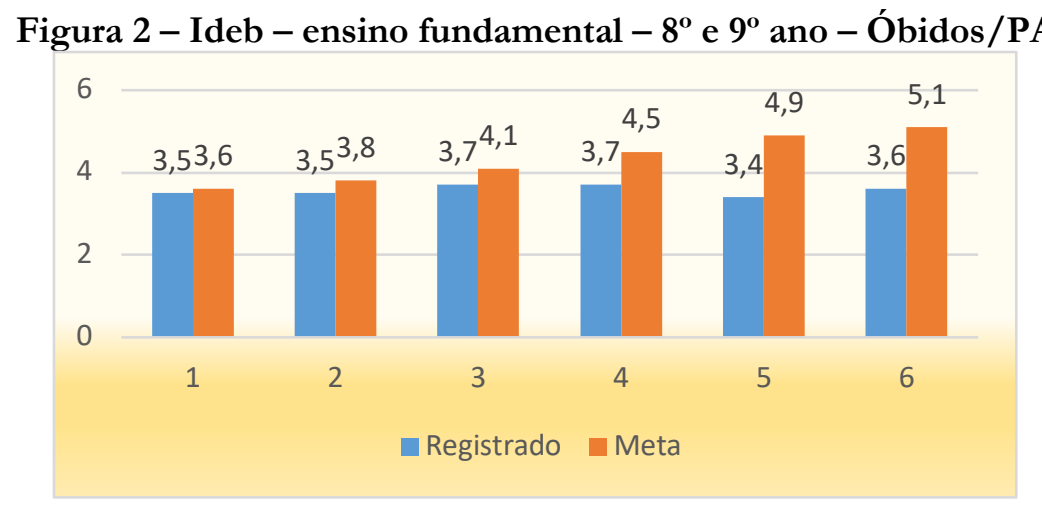

Fonte: Inep.

Segundo Libâneo (2013), as pesquisas que visam fazer a relação entre as avaliações de larga escala e a formação de professores revelam que é necessário que se faça uma análise das condições de formação do profissional que atua no ensino fundamental, pois os resultados dessas avaliações mostram um quadro desolador e as medidas adotadas para melhorar a qualidade do ensino não proporcionam mudanças nesse quadro:

Relatos de pesquisas que buscam estabelecer relações entre os resultados de avaliação em escala referentes à Educação Básica e a formação e desenvolvimento profissional de professores remetem, inevitavelmente, à análise das condições de formação profissional para atuação nos anos iniciais do ensino fundamental. Com efeito, a divulgação desses resultados mostra um quadro desolador da situação do ensino fundamental e das medidas adotadas até o momento tanto as relacionadas às diretrizes curriculares, modelos de formação, carreira e remuneração de professores quanto as relacionadas com formas de intervenção nos fatores intraescolares parecem não ter efeitos na mudança desse quadro (p. 73-74).

Ademais, nesta conjuntura, os entrevistados apontam que entre os fatores que contribuem para que não se alcance a qualidade pretendida, que no caso da avaliação em larga escala é convertida em uma média numérica, há o fato de alguns professores não colocarem em prática os conhecimentos que receberam durante a sua graduação e permanecerem usando metodologias tradicionais. A este respeito, um dos entrevistados declara:

Podemos colocar que 60\% dos professores pegaram todo aquele conhecimento e mudaram as suas práticas na sala de aula, no entanto alguns receberam todo o conbecimento e continuaram com a mesma prática, com a mesma metodologia tradicional (CP-ZU).

Deve-se, certamente, ter em vista que as avaliações em larga escala consideram apenas a aprendizagem dos conteúdos de Língua Portuguesa e Matemática, deixando de lado o contexto em que as escolas estão inseridas, o público que as frequenta e, sobretudo, as condições de trabalho dos docentes. É salutar a reflexão feita pelo gestor do sistema público municipal de educação: "O Parfor melhorou os indices do município, no entanto não é somente o dominio da matemática e do português, que 
DOI: $10.12957 /$ teias. $\%$ Y.50163

influenciam para essa nota, também é levado em consideração a parte física da escola, a frequência dos alunos e a evasão". (G-SEMED)

As avaliações de larga escala tornaram-se o "carro-chefe" das políticas em educação. Gatti, Barreto e André (2011) afirmam que, nas reformas educacionais de modelos gerencialistas, o foco está nos resultados de rendimento escolar dos alunos, medido através de "[...] testes em larga escala, com grande ênfase na eficácia e na eficiência da escola no manejo do currículo. Isso, sem apoiar as escolas no que diz respeito a esse manejo" (p. 31).

O que se constata é que as ações desenvolvidas a partir das políticas de avaliação não são ações com inovações em didática, nos currículos, em materiais didáticos diferenciados dos existentes ou projetos formativos renovadores para a escola, mas sim ações que procuram cobrir lacunas de desempenho dos alunos nessas duas áreas de conhecimento.

Não se pode pensar que exista uma relação de causa e efeito determinística entre o cumprimento das metas e o melhoramento da qualidade da educação. É necessário que se pense em políticas que se preocupem realmente com a qualidade da formação e não apenas com a quantidade de profissionais com a formação exigida por lei.

A partir do ano de implementação do Parfor, o Ideb do município de Óbidos para o ensino fundamental anos iniciais obteve evolução positiva: em 2009, o município apresentou Ideb de 3.7 nesta etapa do ensino fundamental. Já em 2013, o índice subiu para 4.2, sinalizando que, mesmo que ainda em processo formativo, o ingresso desses professores que já estavam atuando na sala de aula em um curso superior contribuiu para essa evolução.

O gráfico apresenta um comparativo entre os ingressantes no curso de Pedagogia e a evolução nos índices do Ideb dos anos iniciais do ensino fundamental.

Figura 3 - Comparativo de evolução do Ideb - anos iniciais, com quantitativo de profissionais formados no curso de Pedagogia pelo Parfor - Óbidos/PA.

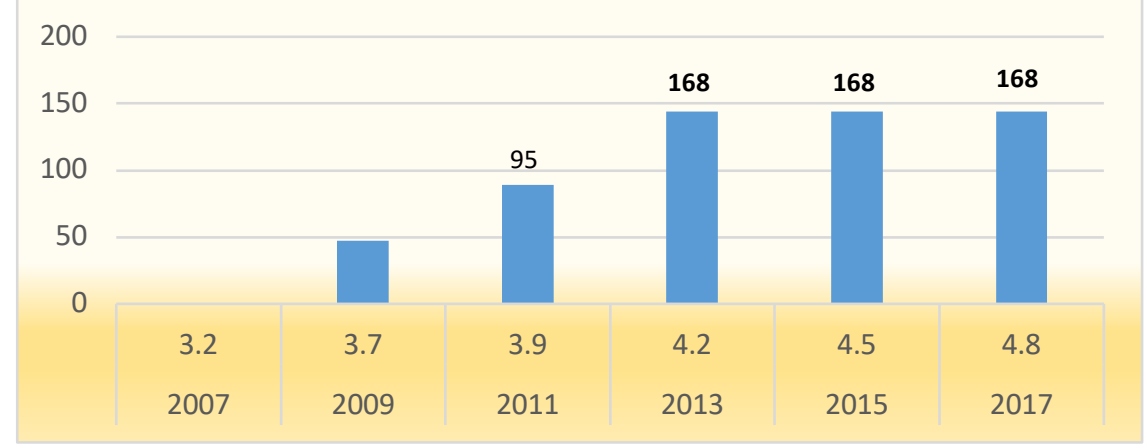

Fonte: Inep/Coordenação Local Parfor.

Conforme relatório da Coordenação Local do Parfor, em 2010, ingressaram 50 docentes no curso de Pedagogia; em 2013, esse quantitativo subiu para 168 docentes em qualificação pelo Parfor. Vê-se que, à medida que o número de ingressos no curso de Pedagogia cresce, o desempenho do município no Ideb também vai se elevando. Assim considerando o que preconiza o Inciso V, do Art. 2, do Decreto n. 8.752/16, e que a articulação entre a teoria e prática no processo de formação é fundamental para uma formação eficiente, infere-se positivamente sobre a contribuição da formação obtida.

Lontra e Emilião (2018) argumentam que: 
DOI: $10.12957 /$ teias.\%Y.50163

[...]a docência é uma aprendizagem complexa que acontece cotidianamente à medida que nos desvelamos para aprender com. Deslocando a visão de professores "transmissorxs" de conhecimentos já elaborados para a de "professores-autorxs" das próprias práticas, abrimo-nos para a possibilidade de criar, de inventar, de construir novas formas de aprenderensinar (p. 399-400).

Faz-se pertinente o pensamento de Gatti (2015) sobre a lacuna observada pelos entrevistados no que se refere à teoria e à prática por parte dos docentes formados pelo Parfor e o desempenho deles no exercício da profissão:

Os espaços destinados nas licenciaturas, pelas normas vigentes no Brasil, ao tratamento concreto das práticas docentes, aliando experiência e teoria, não são aproveitados pelas instituições formadoras para fazer esta rica aliança entre conhecimento acadêmico e conhecimento que vem com o exercício da profissão e com as experiências vividas em situações escolares na educação básica. Encontramos sob este aspecto uma dissonância muito grande entre o proposto legalmente e o defendido nos discursos e o realizado nos cursos de formações de professores (p. 98).

Isto corrobora com a discussão inicial sobre o Parfor atender consideravelmente em termos quantitativos à demanda de formação de professores. Porém, esta rede é descontinuada quando o município deixa de fazer a devida alocação dos profissionais por sua área de formação em correspondência a sua área de atuação, bem como deixa de promover a realização de concursos públicos que visem regularizar a vida funcional destes profissionais, ou ainda, providenciar outra forma que possibilite a continuidade de vínculo profissional com a rede pública.

\section{CONTRIBUIÇÕES DO PARFOR PARA O DESEMPENHO DA ATIVIDADE DOCENTE}

As transformações que nos trouxeram à sociedade contemporânea também impetram à escola e aos professores novos papéis e lhes requerem diferentes competências e habilidades. A escola contemporânea se situa em contextos sócio-político e cultural diferentes: "[...] suas funções mudaram, como sempre foram mudando com o passar do tempo; portanto, o professorado precisa mudar sua forma de trabalhar na escola e na sala de aula" (IMBERNÓN, 2016, p. 86).

Considerando as grandes transformações ocorridas no mundo em que vivemos, em especial as decorrentes da precariedade nas relações de trabalho, tem-se criado um cenário que requer dos professores maior conexão com as demandas sociais, implicando uma formação (ou mais formação) para acompanhar as novas mudanças, pois "[...] se necessita de uma profissão com um novo perfil de competências que assuma os desafios do ensino e da aprendizagem atual e do futuro" (IMBERNÓN, 2016, p. 102).

Considerando este cenário, foi aplicado questionário misto com perguntas abertas e fechadas a 14 professores lotados nas 14 escolas da zona urbana da rede municipal de ensino do município lócus, com o objetivo de verificar as suas percepções acerca das contribuições do Parfor em suas práticas educacionais.

De início, os dados confirmaram que muitos dos profissionais entrevistados já exerciam a docência no ano em que o programa foi implementado no município: 14,3\% dos entrevistados 
tinham experiência docente de 6 a 10 anos, 21,4\% - experiência docente de 11 a 15 anos, 42,9\% experiência docente de 16 a 20 anos e 21,4\% - experiência docente de mais de 21 anos.

Isso remete ao entendimento de que a formação superior veio complementar os anos de experiência em sala de aula que muitos já tinham, porém, traz também um alerta relacionado ao desempenho do município na avaliação de larga escala, pois, se muitos destes profissionais já dispunham de um longo tempo de magistério, seria lógico que o município apresentasse melhores resultados, pelo aprimoramento das práticas educacionais tendo como fundamentação a ação refletida a partir dos conhecimentos teóricos possibilitados pela graduação.

Sobre este aspecto, Bastos (2017) afirma que:

O Parfor vem com essa responsabilidade de possibilitar a formação aos professores que já estão na sala de aula, mas não tem a formação em nível superior. Acredita-se que, através da formação, os professores devem produzir mudanças qualitativas em suas salas de aula e em sua vida profissional (p. 111).

Entre os professores integrantes do estudo, 57,1\% desenvolvem suas atividades no ensino fundamental séries iniciais, sendo que $78,57 \%$ obtiveram a primeira graduação via Parfor, corroborando desta forma com qualidade da educação, ainda que representada numericamente, como apresentado anteriormente com os dados do Ideb.

Questionou-se aos entrevistados a respeito de suas percepções quanto às contribuições da formação obtida para a sua prática profissional. Embora as respostas não definam especificamente quais as contribuições pedagógicas possibilitadas, dão conta de comprovar que os egressos consideram que sua prática pedagógica pode ser aperfeiçoada por meio da formação acadêmica, elencando entre os aspectos que incidem sobre este aperfeiçoamento os conhecimentos científicos a que tiveram acesso, que, aliados ao compromisso dos professores formadores, possibilitaram o desenvolvimento de consciência crítico-reflexiva sobre a atuação profissional:

Uma coisa que posso citar como ponto positivo, são os conhecimentos adquiridos durante a nossa formação acadêmica, conhecimentos esses que vieram somar melhoria na minha vida profissional (SP-1).

Os professores sempre foram muito comprometidos com a formação acadêmica dos alunos e tem responsabilidade com a organização e estrutura do espaço, foi outra coisa que sempre se destacou em nossa formação (SP-9).

Faz-se necessário ressaltar que um dos pontos positivos da formação do PARFOR é que esta contribuiu na formação de minha consciência crítica e reflexiva da prática pedagógica, assim como, me auxiliou na inserção de novos métodos e metodologia em sala de aula e, desta forma possibilitou com que as aulas tornassem mais dinâmicas e atrativas despertando o interesse dos alunos. Assim, a formação pelo Parfor contribuiu de forma significativa no meu enriquecimento metodológico, pautado pela oportunidade de aperfeiçoamento profissional (SP-5).

Parte dos entrevistados declarou ainda que a formação foi desenvolvida por meio de uma proposta acadêmica moderna, com materiais didáticos de qualidade, possibilitando o aperfeiçoamento profissional.

Entre diversos pesquisadores é comum a observação de que, embora haja lacuna nesta formação, há que se reconhecer que a formação pelo Parfor produz mudanças na qualidade do ensino e na vida profissional do professor (BASTOS, 2017, p. 111). 
Provocados sobre as contribuições do Parfor para a inovação nos procedimentos metodológicos na sala de aula, a totalidade dos entrevistados julga que a formação contribuiu positivamente para a melhoria das metodologias de ensino no cotidiano pedagógico.

Em síntese, o Parfor atendeu parte das necessidades de formação dos professores do município de Óbidos e, como outros programas, tem deixado lacunas que apontam um caminho a ser trilhado pelos formuladores das políticas educacionais no sentido de alcançar o que Gatti denomina de "virar a mesa", isto porque foi relatado que a formação alcançada possibilitou que os docentes melhorassem suas práticas pedagógicas, trazendo novas metodologias para sala de aula, que tornaram as aulas mais dinâmicas e atrativas para os discentes. Então, é justo considerar que a formação tenha possibilitado uma consciência crítica e reflexiva diante das práticas pedagógicas.

\section{CONSIDERAÇÕES FINAIS}

O Município de Óbidos-PA aderiu ao Programa Nacional de Professores da Educação Básica (Parfor) no ano de 2009 e as primeiras turmas de cursos de graduação foram ofertadas pela Universidade Federal do Oeste do Pará (Ufopa), no contexto do programa, com início das atividades acadêmicas em 2010.

Atualmente, o quadro de docentes da rede pública municipal de Óbidos contempla cerca de dois terços dos profissionais com a formação graduada condizente com suas respectivas áreas de atuação, conforme preconiza a legislação educacional, apontando para novos horizontes.

O Inep registrou em 2017 que $71 \%$ dos professores da educação básica da rede municipal possuíam a formação superior exigida em lei, sendo que o quadro docente total municipal é integrado em 46,6\% (258) por profissionais egressos do Parfor.

Este fato coloca o Parfor como um programa que trouxe melhorias para as práticas pedagógicas dos professores, percebidas nos resultados das avaliações de larga escala dos anos iniciais. Por outro lado, é reconhecida a existência de fragilidades que refletem em baixos resultados das avaliações nos anos finais do ensino fundamental, etapa que apresenta comprometimento significativo das metas projetadas.

É importante destacar que a preocupante situação educacional do município é decorrente de outros fatores, como a ausência de uma política de valorização e de remuneração destes profissionais que inclui também as condições de trabalho, marcado por avanços das legislações, que, contudo, não se materializam nas unidades escolares.

O Parfor deve ser reconhecido como o mais importante programa de formação de professores e que traz um grande simbolismo para uma sociedade cada vez mais ávida de direitos a serem conquistados. Sua relevância se dá, sobretudo, quando pensamos no professor da Amazônia paraense, especialmente do meio rural, onde há ainda maior dificuldade de chegada da presença do Estado brasileiro.

A oferta do programa reavivou interesses e sonhos por parte dos docentes da rede pública. Isso porque, por meio dele, muitos que não nutriam mais possibilidades de ter uma formação em nível superior puderam alcançá-la e isso reacendeu nestes novos horizontes para a permanência no mercado de trabalho.

$\mathrm{Na}$ óptica dos gestores e coordenadores da Secretaria Municipal de Educação, o programa contribuiu para a formação de quadros docentes da educação básica no município, pois, antes de sua implementação, o quadro de professores era composto, na maioria, por professores sem a qualificação exigida por lei, além de que o programa também trouxe uma grande oportunidade para 
os profissionais das áreas mais afastadas, como região de rios e planalto, onde a educação superior raramente chega.

Em outra óptica, os professores egressos do programa consideram que o Parfor contribuiu para o desempenho de sua atividade profissional, uma vez que a formação possibilitou que os docentes otimizassem suas práticas pedagógicas, resultando em novas metodologias para a sala de aula, que tornaram as aulas mais dinâmicas e atrativas para os alunos.

Destaca-se que é preciso debater sobre a formação do professor em relação à qualidade da educação em nível municipal e, ao mesmo tempo, sobre o caminho que deve ser trilhado pelos gestores públicos ao proporem mudanças para que o município possa avançar para outro patamar no cenário nacional.

É fundamental que os gestores públicos reconheçam a importância do programa e, em encaminhamentos locais, considerem a existência de professores formados com a qualificação exigida em lei, alocando-os em áreas de atuação correspondentes às áreas de formação, bem como promovam a realização de concursos públicos que regularizem a vida funcional destes profissionais, ou ainda, providenciem outra forma que possibilite a continuidade de vínculo profissional com a rede pública, garantindo aos egressos do Parfor possibilidades de continuar colaborando com a rede pública de ensino.

O Parfor deixa para o município um importante legado com professores, tanto com a primeira graduação, como também outros com a segunda graduação, o que significa um importante avanço do ponto de vista legal na mesma medida em que aponta uma reflexão sobre práticas até então sedimentadas no cotidiano da escola. Isso porque há o contato dos docentes com outros docentes de realidades diferentes, haja vista que a realidade obidense se divide em área urbana, área de terra firme e área de várzea, pertencentes à mesma jurisdição educacional, mas que apresentam, cada uma, contextos e peculiaridades distintas que trazem para a experiência docente saberes importantes para a sua prática e que, aliadas ao conhecimento de professores do Parfor com uma sólida formação acadêmica, contribuem para o aprimoramento do saber-fazer pedagógico.

Por fim, pode-se concluir que os efeitos do Parfor sobre a educação municipal em ÓbidosPará são mais elucidados nos aspectos quantitativos, e, de maneira generalizada, os efeitos da formação são mais contundentes no primeiro ciclo do ensino fundamental do que no segundo, apontando para a necessidade de novas abordagens investigativas que, entre outras possibilidades, permitam compreender as razões deste fenômeno.

\section{REFERÊNCIAS}

BASTOS, Jaqueline Mendes. Plano Nacional de Formação de Professores da Educação Básica-Parfor. Concepções, Diretrizes e Princípios Formativos. Programa de Pós-Graduação em Educação. Doutorado em Educação. Capes: teses e dissertações. Cametá, PA, 2017.

BORGES, Maria Célia. Formação de Professores: Desafios Históricos, Políticos e Práticos. São Paulo: Paulus, 2013.

BRASIL. Decreto n. 6.755, 29 jan. 2009. Institui a Política Nacional de Formação de Profissionais do Magistério da Educação Básica, disciplina a atuação da Coordenação de Aperfeiçoamento de Pessoal de Nivel Superior - CAPES no fomento a programas de formação inicial e continuada, e dá outras providências. Disponível em https://capes.gov.br/images/stories/download/legislacao/Decreto-6755-2009.pdf. Acesso em 18 nov. 2018. 
DOI: $10.12957 /$ teias. $\%$ Y.50163

BRASIL. Decreto n. 8.752, 09 maio 2016. Dispõe sobre a Política Nacional de Formação dos Profissionais da Educação Básica. Disponível em http://www.planalto.gov.br/ccivil 03/ Ato20152018/2016/Decreto/D8752.htm\#art19. Acesso em 18 nov. 2018.

BRASIL. Lei n. 9.394, 20 dez. 1996. Estabelece as diretrizes e bases da educação nacional. Brasília - DF, dez. 1996. Disponível em http://www.planalto.gov.br/ccivil 03/LEIS/L9394.htm. Acesso em 18 nov. 2018.

BRASIL. Lei n. 13.005, 25 jun. 2014. Aprova o Plano Nacional de Educaşão - PNE e dá outras providências, Brasília - DF, jun. 2014. Disponível em www.planalto.gov.br/ccivil_03/_ato20112014//2014/lei/113005.htm. Acesso em 19 nov. 2018.

GATTI, Bernardete Angelina. Formação de professores: compreender e revolucionar. In: GATTI, Angelina Bernardete, et. al. (org.). Por uma revolução no campo da formação de professores. $1^{a}$ ed. São Paulo: Editora Unesp, 2015. p. 229-243.

GATTI, Bernardete Angelina; BARRETO, Elba Siqueira de Sá; ANDRE, Marli Eliza Dalmazo de Afonso. Políticas Docente no Brasil: um estado da arte. Brasília: UNESCO, 2011.

IMBERNÓN, Francisco. Formação docente e profissional: formar-se para a mudança e a incerteza. 9. ${ }^{a}$ ed. São Paulo: Cortez, 2011.

IMBÉRNON, Francisco. Qualidade do ensino e formação do professorado: uma mudança necessária. São Paulo: Cortez, 2016.

LIBÂNEO, José Carlos. Licenciatura em Pedagogia: a ausência dos conteúdos específicos do ensino fundamental. In: GATTI, Angelina Bernardete. et. al. (org.). Por uma política nacional de formação de professores. São Paulo: Editora Unesp, 2013. p. 73-94.

LONTRA, Viviane; EMILIÃO, Soymara Vieira. Tessituras e reinvenções: (des)formação de professores. Revista Teias. v. 19, n. 54, jul./ set. 2018. Cotidianos, Políticas e Avaliação. Disponível em https://www.e-publicacoes.uerj.br/index.php/revistateias/article/view/34692. Acesso em 20 mar. 2020.

SOUZA, Edinilza Magalhães da Costa. O plano de formação docente/Parfor e a inter-relação com o regime de colaboração no estado do Pará. Tese (Doutorado em Educação). Programa de Pós-Graduação em Educação, UFPA, Belém, PA, 2018.

\section{Informações das autoras}

Aline da Silva Ferreira

Universidade Federal do Oeste do Pará

E-mail: a_lineferreira@outlook.com

ORCID: https://orcid.org/0000-0001-6670-1270

Link Lattes: http://lattes.cnpq.br/7923456943705204 
Iamília Brito de Oliveira

Universidade Federal do Oeste do Pará

E-mail:iamiliabrito@yahoo.com.br

ORCID: https://orcid.org/0000-0002-8115-1606

Link Lattes: http://lattes.cnpq.br/5972034059629663

Lílian Aquino Oliveira

Universidade Federal do Oeste do Pará

E-mail: lilian.oliveira@ufopa.edu.br

ORCID: https://orcid.org/0000-0001-9607-7296

Link Lattes: http://lattes.cnpq.br/0533551187538327 